\title{
THE EFFECT OF ZIRCONIA BAND AND LOOP SPACE MAINTAINER ON SALIVARY LEVEL OF LACTOBACILLUS AND STREPTOCOCCUS MUTANS
}

\author{
Baher Emad Mohamed Mahmoud ${ }^{1 *}$, Ibrahim Farouk Barakat ${ }^{2}$, Mohamed Galal Ibrahim AboElsau'd ${ }^{3}$, \\ Amani Mohammed Tawfik Ahmed ${ }^{4}$
}

\begin{abstract}
Objective of this study was to evaluate the effect of the zirconia band and loop space maintainers on the salivary level of lactobacillus and streptococcus mutans. Subjects and methods: This study was carried out on fifty children classified into two equal groups, Group A: Twenty-five children have received metal bands and loops space maintainers. Group B: Twentyfive children have received zirconia bands and loops space maintainers. A fresh unstimulated whole saliva sample was collected from each patient before the insertion of the space maintainer, after 2 weeks and three months after its insertion. The mean and standard deviation values were calculated for each viable counts of antibacterial activity, then transformed into their log 10 values. Results: It was found that both zirconia space maintainer and band and loop space maintainer increase bacterial count insignificantly. Conclusion: Zirconia space maintainer can be used as an alternative to a conventional band and loop space maintainer.
\end{abstract}

KEYWORDS: Zirconia, space maintainer, S.mutans, L.acedophilus

\section{INTRODUCTION}

Dental caries is the most common chronic disease of childhood ${ }^{(1)}$. Dental caries is a multifactorial chronic bacterial disease that causes demineralization and destruction of the hard tissues usually by the production of acid by bacterial fermentation of the food debris accumulated on the tooth surface ${ }^{(2)}$. It was reported that microorganisms believed to lead to the occurrence of caries within the oral flora, Streptococcus mutans (S. mutans) and Lactobacillus acidophilus (L. acidophilus) play major roles in this process ${ }^{(3)}$.
The study of the level of S. mutans in the saliva is one of the most common methods for identifying subjects at risk of dental caries ${ }^{(4)}$. A strong correlation has been established between the lactobacillus count and caries, the higher the DMF index, the higher the number of children harboring a high lactobacillus count ${ }^{(5)}$.

Primary teeth play a critical role in the growth and development of a child. In addition to their role in esthetics, eating, speech, and to encourage normal function and resultant expected growth,

1. Masters Candidate, Pedodontics and Oral Health Department, Faculty of Dental Medicine, Boys, Cairo, Al Azhar University.

2. Associate Professor, Pedodontics and Oral Health Department, Faculty of Dental Medicine, Boys, Cairo, Al-Azhar University.

3. Lecturer, Pedodontics and Oral Health Department, Faculty of Dental Medicine, Boys, Cairo, Al Azhar University.

4. Associate Professor, Microbiology Department, Faculty of Medicine, Girls, Cairo, Al-Azhar University.

-Corresponding author: baherem1611@gmail.com 
the other main function of a primary tooth is to hold space for the permanent successor until it is ready to erupt ${ }^{(6,7)}$. However, if premature extraction or loss of a tooth is unavoidable due to extensive caries or other reasons, the safest option to maintain arch space is by placing a space maintainer ${ }^{(8)}$.

Among the various space maintainers used in pediatric dentistry, metal bands and loops are the most commonly used fixed space maintainers, with the appliances acting as a plaque retentive causing gingival enlargement, mucosal overgrowth on the loop, band displacement causing blanching of the gingiva, loop impingement on the mucosa causing ulceration, pain, and cement disintegration around the band ${ }^{(9)}$. These disadvantages lead to the development of more aesthetic and metal-free space maintainers such as zirconia band and loop space maintainer. Zirconia space maintainer seems to be a suitable alternative to the conventional band and loop space maintainer. The appliance is well tolerated by the patient and also gives the benefit of advanced aesthetics with improved strength. Zirconia is available in all the vita classic and gingival shades which would fulfill the aesthetic demands of the patient ${ }^{(10)}$.

\section{SUBJECTS AND METHODS}

This study was an intervention randomized clinical trial study, and was carried out on fifty selected Egyptian children indicated to space maintainer from the Pediatric Dental Outpatients Clinic, Faculty of Dental Medicine, Al-Azhar University. The age of children ranged from 4 to 8 years.

A sample size of 25 children in each group has an $80 \%$ power to detect a difference between means of 0.09 with a significance level (alpha) of 0.05 (twotailed) at a $95 \%$ confidence interval. In $80 \%$ (the power) of those experiments, the P-value was less than 0.05 (two-tailed) so the results were deemed "statistically significant". In the remaining $20 \%$ of the experiments, the difference between means was deemed "not statistically significant".
Inclusion criteria ${ }^{(11)}$ included children of between 4 - 8 years old, cooperative patients and parents, and normal primary molars relationship. Exclusion criteria (11) included carious buccal and lingual surfaces of affected teeth, crowding, abnormal oral habits, and patients with high caries risk assessment.

\section{Intervention}

Impressions for group A of the upper and lower arches were made by alginate material, then sent to the lab for fabrication of band and loop space maintainer, Figure (1). Impressions for group $\mathrm{B}$ of the upper and lower arches were made by elastomeric impression material, then sent to the lab for fabrication of zirconia space maintainer, Figure (2). A fresh unstimulated whole saliva sample was collected from each patient by asking each child to spit in a sterile container (1st thing after getting up or at least 2 hours after a meal). The samples were collected before the insertion of the space maintainer, after 2 weeks and three months after its insertion. For determining S. mutans salivary levels, mitis salivarius with bacitracin agar was used according to the manufacturer's instructions. The same procedure was used to determine L. acidophilus salivary levels but using selective MRS Agar.

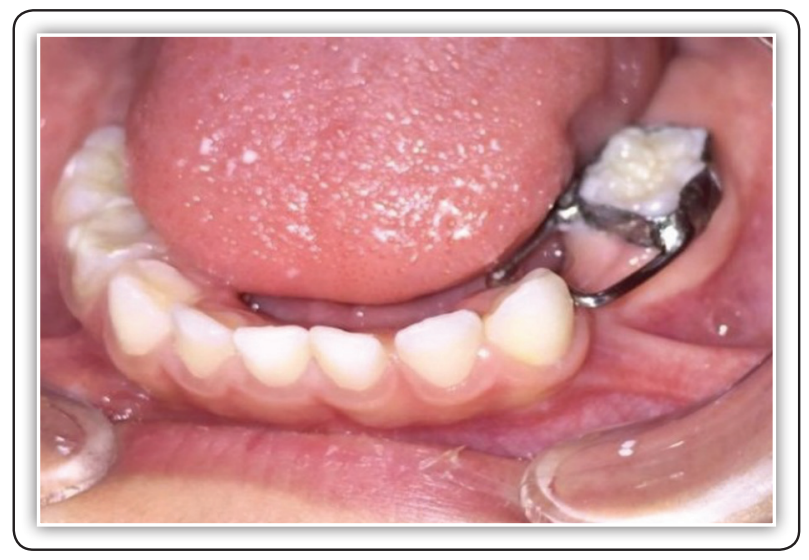

FIG (1) Band and loop space maintainer. 


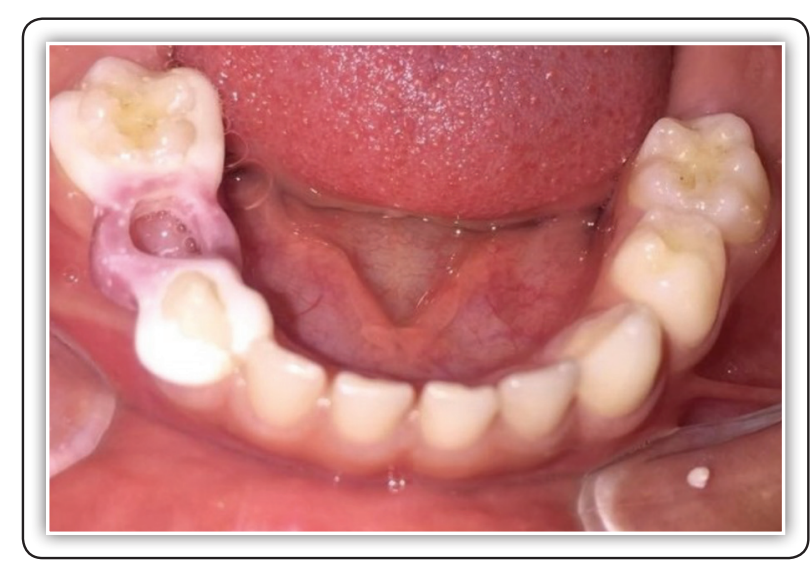

FIG (2) Zirconia band and loop space maintainer.

\section{Ethical consideration}

The study was approved by the pedodontics scientific Committee and department council (EC Ref No.: 155/012019/105G), Faculty of Dental Medicine, Boys, Cairo, Al-Azhar University. Signed informed consent was done from the parents of each child before beginning the study

\section{Statistical Analysis}

The mean and standard deviation values were calculated for each. Viable counts of antibacterial activity were transformed into their $\log 10$ values. Data were explored for normality using Kolmogorov-Smirnov and Shapiro-Wilk tests and antibacterial activity showed parametric (normal) distribution.

\section{RESULTS}

The mean and standard deviation values were calculated for each group. The significance level was set at $P \leq 0.05$. Statistical analysis was performed with IBM ${ }^{\circledR}$ SPSS ${ }^{\circledR}$ Statistics Version 20 for Windows.

\section{Effect of groups on antibacterial activity for S. mutans, table (1) and figure (3):}

\section{- Before insertion:}

There was no statistically significant difference between (Group A) and (Group B) where ( $p=0.660)$.
The highest mean value was found in (Group A) while the least mean value was found in (Group B).

\section{- After 2 weeks:}

There was no statistically significant difference between (Group A) and (Group B) where $(p=0.268)$. The highest mean value was found in (Group A) while the least mean value was found in (Group B).

\section{- After 3 months:}

There was no statistically significant difference between (Group A) and (Group B) where ( $p=0.194)$. The highest mean value was found in (Group A) while the least mean value was found in (Group B).

TABLE (1): The mean, standard deviation (SD) values of $\mathrm{S}$. mutants in different groups for each time period.

\begin{tabular}{|c|c|c|c|c|c|c|c|}
\hline \multirow{3}{*}{ Variables } & \multicolumn{7}{|c|}{ S. mutants } \\
\hline & \multicolumn{2}{|c|}{$\begin{array}{c}\text { Before } \\
\text { insertion }\end{array}$} & \multicolumn{2}{|c|}{ After 2 weeks } & \multicolumn{2}{|c|}{$\begin{array}{l}\text { After } 3 \\
\text { months }\end{array}$} & \multirow[t]{2}{*}{ p-value } \\
\hline & Mean & SD & Mean & SD & Mean & SD & \\
\hline Metal & $6.423^{\mathrm{aA}}$ & 0.069 & $6.459^{\mathrm{aA}}$ & 0.086 & $6.465^{\mathrm{aA}}$ & 0.079 & $0.071 \mathrm{~ns}$ \\
\hline Zirconia & $6.409^{\mathrm{aA}}$ & 0.078 & $6.421^{\mathrm{aA}}$ & 0.070 & $6.423^{\mathrm{aA}}$ & 0.071 & $0.085 n s$ \\
\hline p-value & \multicolumn{2}{|c|}{$0.660 \mathrm{~ns}$} & \multicolumn{2}{|c|}{$0.268 \mathrm{~ns}$} & \multicolumn{2}{|c|}{$0.194 \mathrm{~ns}$} & \\
\hline
\end{tabular}

Means with different small letters in the same column indicate a statistically significant difference, means with different capital letters in the same row indicate a statistically significant difference. *; significant $(\mathrm{p}<0.05) \quad \mathrm{ns}$; non-significant $(\mathrm{p}>0.05)$.

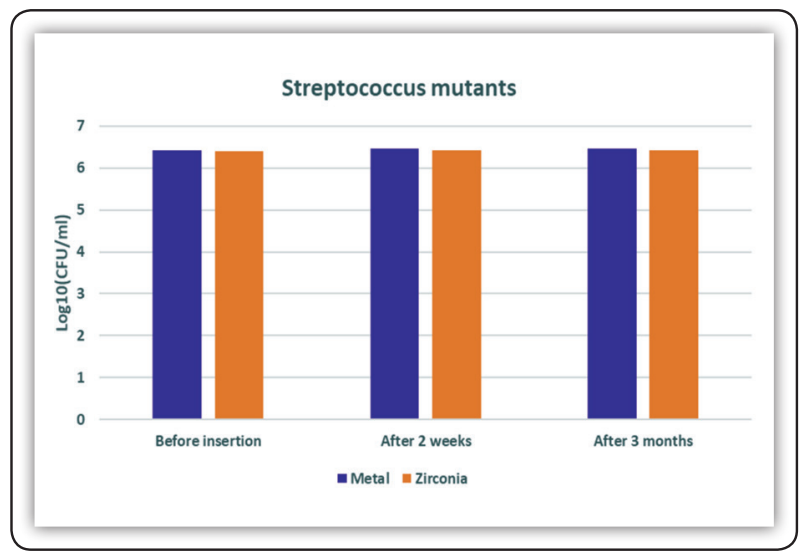

FIG (3) Bar chart representing S. mutants in different groups for each time period. 


\section{Effect of groups on antibacterial activity for} L. acidophilus, table (2) and figure (4):

\section{- Before insertion:}

There was no statistically significant difference between (Group A) and (Group B) where ( $p=0.950)$. The highest mean value was found in (Group A) while the least mean value was found in (Group B).

\section{- After 2 weeks:}

There was no statistically significant difference between (Group A) and (Group B) where ( $\mathrm{p}=0.843$ ). The highest mean value was found in (Group A) while the least mean value was found in (Group B).

\section{- After 3 months:}

There was no statistically significant difference between (Group A) and (Group B) where ( $\mathrm{p}=0.792)$. The highest mean value was found in (Group A) while the least mean value was found in (Group B).

TABLE (2): The mean, standard deviation (SD) values of L. acidophilus in different groups for each time period.

\begin{tabular}{|c|c|c|c|c|c|c|c|}
\hline \multirow{3}{*}{ Variables } & \multicolumn{7}{|c|}{ L. acidophilus } \\
\hline & \multicolumn{2}{|c|}{$\begin{array}{c}\text { Before } \\
\text { insertion }\end{array}$} & \multicolumn{2}{|c|}{ After 2 weeks } & \multicolumn{2}{|c|}{$\begin{array}{l}\text { After } 3 \\
\text { months }\end{array}$} & \multirow{2}{*}{ p-value } \\
\hline & Mean & SD & Mean & SD & Mean & SD & \\
\hline Metal & $6.226^{\mathrm{aA}}$ & 0.067 & $6.239^{\mathrm{aA}}$ & 0.085 & $6.250^{\mathrm{aA}}$ & 0.084 & $0.209 \mathrm{~ns}$ \\
\hline Zirconia & $6.224^{\mathrm{aA}}$ & 0.088 & $6.232^{\mathrm{aA}}$ & 0.075 & $6.240^{\mathrm{aA}}$ & 0.084 & $0.099 \mathrm{~ns}$ \\
\hline p-value & \multicolumn{2}{|c|}{$0.950 \mathrm{~ns}$} & \multicolumn{2}{|c|}{$0.843 n s$} & \multicolumn{2}{|c|}{$0.792 n s$} & \\
\hline
\end{tabular}

Means with different small letters in the same column indicate a statistically significant difference, means with different capital letters in the same row indicate a statistically significant difference. *; significant $(\mathrm{p}<0.05) \mathrm{ns}$; non-significant $(\mathrm{p}>0.05)$.

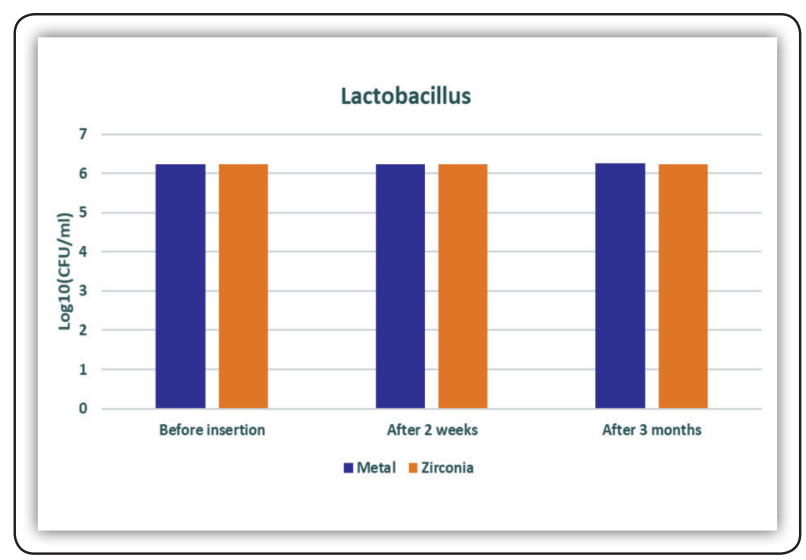

FIG (4) Bar chart representing L. acidophilus in different groups for each time period.

\section{DISCUSSION}

Assessment of caries risk is an important part of the dental practice, notably in the prevention of caries pathologies ${ }^{(12)}$. The originality of the present study was to evaluate the evolution of caries risk factors with salivary microbial parameters in a population of children with two types of fixed space maintainers ${ }^{(13,14)}$.

The study of the level of S. mutans in the saliva is one of the most common methods for identifying subjects at risk of dental caries ${ }^{(4)}$. Nevertheless, a strong correlation has been established between the Lactobacillus count and caries, the higher caries, the higher the number of children harboring a high Lactobacillus count ${ }^{(5)}$.

In the present study, there was no significant difference in the count of L. acidophilus species and S. mutans before insertion of zirconia band and loop space maintainer, after 2 weeks and after 3 months. These results may be due to regular surfaces on band and loop space maintainer, good soldering between band and loop, and proper design of space maintainer. In the zirconia band and loop space maintainer, these results may be due to the remarkable biocompatibility of zirconia which leads to the lower tendency of plaque build-up. 
These results in agreement with Jalalian et $\mathrm{al}^{(15)}$ who evaluate the In-vitro adhesion of S. mutans to zirconia, porcelain, titanium alloy, and indirect composite resin and concluded that zirconia showed the lowest bacterial adhesion in comparison to other tested materials and enamel. Also, these results are supported by (Abbas et al ${ }^{(16)}$ who reported that zirconia crowns adhere to fewer streptococcus colonies compared to lithium disilicate and gold crowns and attributed these results due to higher biocompatibility of zirconia.

The results of the present study were disagreed with Maret et al., that was reported a significant increase in S. mutans and L. acidophilus in saliva was found after 6 weeks from the start of fixed orthodontic therapy and the highest levels were registered at the 12th week of therapy. when assessing the microbial changes in children with fixed orthodontic appliances compared with a control group of children without orthodontic treatment, over a period of six months. This increase in S. mutans following placement of orthodontic devices can be explained by the irregular nature of their surfaces, which promote the growth of these aciduric and acidogenic bacteria that prefer hard surfaces to grow on ${ }^{(17)}$.

On the other hand, these results were disagreed with (Subramanyam and Gurunathan (18) that was evaluating microbial adhesion between two commercially types of SSCs in primary molars and concluded that there was no statistically significant difference seen in the microbial count between the $3 \mathrm{M}$ and Kids crown and natural teeth however the drawback of this study was the short duration of follow up 1 week.

According to AlShaibah et al ${ }^{(19)}$, who evaluate the adhesion of S. mutans to veneered and SSCs and reported that adhesion of $\mathrm{S}$. mutans to veneered crowns was higher than to SSC, and attributed these results due to surface properties of the composite which used as veneers such as chemical composition, surface free energy including surface roughness enhance microbial adhesion.

\section{CONCLUSION}

From the results of the present study, the following conclusions could be drawn:

1. A zirconia space maintainer can be used as an alternative to a conventional band and loop space maintainer.

2. Both Zirconia space maintainer and band and loop space maintainer increase bacterial count insignificantly.

3. The acceptability of the child to zirconia space maintainer is more than band and loop space maintainer.

\section{REFERENCES}

1. Bach K and Manton D. Early childhood caries New Zealand perspective. J of Primary Health Care 2014; 6:169-74.

2. Vos T, Flaxman A and Naghavi M. Years lived with disability (YLDs) for 1160 sequelae of 289 diseases and injuries 1990-2010: a systematic analysis for the Global Burden of Disease Study 2010. Lancet 2012;15: 2163-96.

3. Karaolanoglu S and Akgul H. The association between the DMFs index and levels of salivary S. mutans and lactobacilli of subjects living in ErzurumTurkey. $\mathrm{J}$ of Dent Sci 2010;5 :70-4.

4. Petti S, Pezzit R, Cattaruzza M, Osborn J, and Arca S. Restoration related salivary S. mutans level dental caries risk factor. J of Dentistry 1997; 25: 251-62.

5. Hasslof P, Hedberg M, Twetman S and Stecksen C. Growth inhibition of oral mutans streptococci and candida by commercial probiotic lactobacilli - an in vitro study. BMC Oral Health 2010; 2:10-18.

6. Bijoor R and Kohli K. Contemporary space maintenance for the pediatric patient. N Y State Dent J 2005; 71:32- 5 .

7. Tunc E, Bayrak S, Tuloglu N, Egilmes T, and Isci D. Evaluation of survival of 3 different fixed space maintainers. Pediatric Dentistry 2012;34 :97-102.

8. Setia V, Pandit I, Srivastava N, Gugani N, and Gupta M. Banded vs bonded space maintainers finding the better way out. Int J Clin Pediatr Dent 2014;7 :97-104.

9. Chandra S, Krishnamoorthy K, Jency Samue, Johnson $\mathrm{J}$ and Prabhup L. effects of Conventional band and loop space maintainers: Time to revolutionise. Med J Adv Res. 2018;4, 1-3 
10. Soni H. Application of CAD-CAM for Fabrication of Metal-Free Band and Loop Space Maintainer. J of Clin Diagn Res. 2017; 11:14- 6.

11. Subramaniam P, Babu K, and Sunny R. Glass fiber-reinforced composite resin as a space maintainer aclinical study. J of Indian Soc Pedod Prevent Dent 2008;98-103.

12. Perosa K, Mestrovicb S, Milosevic S and Slajd M. Salivary microbial and non-microbial parameters in children with fixed orthodontic appliances. Angle Orthodontist 2011; 81: 901- 6 .

13. Samadah M, El Bayoumy S, and El- Mansy T. "Assessment of salivary microbial parameters with two types of fixed space maintainers in children". Al-Azhar J of Dental Science, 21, 5, 2018, 421-426.

14. Siudikiene J, Machiulskiene V, Nyvad B, Tenovuo J, and Nedzelskiene I. Dental caries and salivary status in children with type 1 diabetes mellitus, related to the metabolic control of the disease. Eur J Oral Sci. 2006; 114:8-14.
15. Jalalian E, Mostofi S, Shafiee E, Nourizadeh A and Nargesi R. Adhesion of S. mutans to zirconia, titanium alloy, and some other restorative materials: "An in-vitro study". AIAC. 2014;3 :13-9.

16. Abbas I, Sara H and Zuryati G. Bacterial adhesion on zirconia, lithium disilicate and gold crowns-in vivo study. Adv Dent and Oral Health. 2016; 1:1-3.

17. Maret D, March C, Vergne J, Hamel O, Gurgle M, et al. Effect of fixed ortho- dontic appliances on salivary microbial parameters at 6 months controlled observational study. J Appl Oral Sci 2014; 22:38-43.

18. Subramanyam D and Gurunathan D. Microbial evaluation of plaque on 3M ESPE and kids stainless steel crown in primary molars. Int J Pedod Rehabil. 2016; 1:60-3.

19. Alshaibah WMB, El-Shehaby FA, El-Dokky NA, Reda AR. Comparative study on the microbial adhesion to preveneered and stainless steel crowns. J of Indian Soc Pedod Prevent Dent 2012;30(3): 206-11. 